\title{
PERBEDAAN STATUS ORAL HIGIENE DAN PERIODONTAL PASIEN KOMPROMIS DAN NON KOMPROMIS MEDIS RAWAT INAP DI RSUP H. ADAM MALIK MEDAN
}

\section{(COMPARATIVE OF ORAL HYGIENE AND PERIODONTAL STATUS OF HOSPITALIZED MEDICALLY COMPROMISED AND NON-COMPROMISED PATIENTS IN CENTRAL GENERAL HOSPITAL H. ADAM MALIK MEDAN)}

\author{
Herniza Yusdani*, Sondang Pintauli**, Dharma Lindarto**** \\ *Program Studi Magister Ilmu Kedokteran Gigi \\ **Departemen Ilmu Kedokteran Gigi Pencegahan/Kesehatan Gigi Masyarakat, \\ Fakultas Kedokteran Gigi, Universitas Sumatera Utara \\ Jl. Alumni No. 2 Kampus USU Medan-20155 \\ ****Departemen Penyakit Dalam, Fakultas Kedokteran, Universitas Sumatera Utara \\ Jl. Dr. T. Mansur No. 5 Kampus USU Medan-20155
}

\begin{abstract}
Hospitalized medically compromised condition has long been known as a potential risk factor to the incidence of periodontal disease. Many studies reported about the correlation between medically compromised patients and periodontal disease. The objective of this study was to analyze oral hygiene and periodontal status in hospitalized medically compromised and non-compromised patients in Central General Hospital H. Adam Malik Medan. This case control design study used 60 medically compromised patients (cardiovascular disease and type 2 Diabetes mellitus) and 60 non-compromused patients (ear, nose, and throat disease and sore eye). To measure oral hygiene used oral hygiene Index and to measure periodontal status used Periodontal Disease Index (PDI) Ramfjord. The results showed that 73.3\% of medically compromised patients had poor oral hygiene and $64.7 \%$ periodontitis. Otherwise, $70 \%$ of non-compromised patients had good oral hygiene and $35.3 \%$ periodontitis. Odds ratio of hospitalized medically compromised patients for oral hygiene was 6.4 and periodontal disease was 2.8 . In conclusion, medically compromised patients, especially cardiovascular and type 2 Diabetes mellitus patients had oral hygiene 6 times worse and 3 times higher risk of periodontitis than non-compromised patients.
\end{abstract}

Key words: oral hygiene, periodontal status, compromised patient, hospitalized

\begin{abstract}
Abstrak
Kondisi kompromis medis, terutama pada pasien rawat inap di rumah sakit, telah lama diketahui sebagai faktor risiko yang berpotensi terhadap terjadinya penyakit periodontal. Banyak penelitian yang telah dilaporkan mengenai hubungan kondisi kompromis medis dengan penyakit periodontal. Tujuan penelitian ini adalah untuk menganalisis status oral higiene dan periodontal pasien kompromis dan non kompromis medis rawat inap di Rumah Sakit Umum Pusat H. Adam Malik Medan. Desain penelitian ini adalah kasus kontrol dengan 60 pasien kompromis medis (penderita penyakit jantung dan Diabetes melitus tipe 2) dan 60 pasien non kompromis medis (penderita penyakit THT dan mata). Digunakan Oral Hygiene Index Simplified (OHI-S) untuk mengukur status oral higiene dan Periodontal Disease Index (PDI) oleh Ramfjord. Hasil penelitian menunjukkan bahwa 73,3\% pasien kompromis medis mempunyai oral higiene buruk dan $64,7 \%$ periodontitis. Sebaliknya, $70 \%$ pasien non kompromis medis mempunyai oral higiene baik dan 35,3\% periodontitis. Odds ratio oral higiene terhadap pasien rawat inap kompromis medis adalah 6,4 dan penyakit periodontal terhadap pasien rawat inap kompromis medis 2,8. Sebagai kesimpulan, pasien kompromis medis terutama penyakit jantung dan DM tipe 2 mempunyai oral higiene 6 kali lebih buruk dan 3 kali lebih berisiko periodontitis dibandingkan pasien non kompromis medis.
\end{abstract}

Kata kunci: oral higiene, status periodontal, pasien kompromis medis, rawat inap 


\section{PENDAHULUAN}

Pasien kompromis medis adalah pasien dengan penyakit sistemik yang harus dikompromikan terlebih dahulu sebelum dilakukan tindakan medis sehingga menyebabkan keterbatasan melakukan aktivitas normal sehari-hari. ${ }^{1}$ Kondisi kompromis medis dikategorikan ke dalam 8 kelompok yaitu: (1) gangguan kardiovaskuler, (2) gangguan perdarahan, (3) gangguan pernafasan, (4) gangguan endokrin, (5) gangguan sistem imun, (6) gangguan neurologi, (7) gangguan pencernaan, dan (8) gangguan ginjal. ${ }^{2}$ Ha-sil penelitian Dhanuthai et al. tahun 2002-2004 di Thailand menyatakan penyakit jantung $(32,94 \%)$ dan diabetes $(17,94 \%)$ sebagai kondisi kompromis medis yang paling umum terjadi. ${ }^{3}$

Oral higiene yang buruk dan akumulasi plak gigi merupakan penyebab utama terjadinya inflamasi gingiva, juga termasuk salah satu faktor risiko memburuknya status kesehatan sistemik pasien kompromis medis rawat inap di rumah sakit yang menyebabkan perkembangan komplikasi lokal dan sistemik lainnya di rongga mulut. Penelitian Neto et al. yang dilakukan di Rumah Sakit Londrina, Brazil menemukan bahwa status kesehatan mulut pasien rawat inap di rumah sakit adalah buruk dan sebagian besar pasien membutuhkan perawatan kesehatan mulut. ${ }^{4}$ Penelitian Barilli, et al. tahun 2006 pada penyakit jantung di Rumah Sakit Pendidikan Sao Paulo Brazil menyatakan 79,3\% pasien membutuhkan perawatan terhadap periodontitis. ${ }^{5}$ Penelitian Marjanovic dan Buhlin pada pasien dengan diagnosis penyakit jantung dan DM yang berobat ke Fakultas Kedokteran Gigi Karolinska, Swedia menunjukkan sebanyak 44,3\% pasien penyakit jantung dan $21,2 \%$ pasien DM menderita periodontitis. ${ }^{6}$

Sampai saat ini masalah gigi dan mulut masih menjadi masalah nasional di Indonesia. Hasil Riset Kesehatan Dasar tahun 2013 menyatakan prevalensi nasional masalah gigi dan mulut adalah $25,9 \%$ dan hanya $31,1 \%$ saja masyarakat yang menerima perawatan dari tenaga medis gigi (dokter gigi spesialis, dokter gigi, dan perawat gigi). ${ }^{7}$ Hasil penelitian Situmorang pada masyarakat di 2 kecamatan Kota Medan menunjukkan tingginya prevalensi penyakit periodontal sebesar 96,58\% dengan kebutuhan perawatan karang gigi sebesar $85,18 \% .{ }^{8}$ Faktor-faktor risiko yang berkontribusi terhadap memburuknya status kesehatan rongga mulut pada pasien rawat inap di rumah sakit meliputi usia lanjut, jenis kelamin, tidak adanya instruksi oral higiene, adanya komplikasi penyakit sistemik, dan lamanya waktu dirawat inap di rumah sakit. ${ }^{4}$ Sebagian besar masyarakat jarang melakukan pemeriksaan kesehatan umum secara rutin sehingga tidak menyadari bahwa mereka mengalami gejala awal penyakit kompromis medis seperti penyakit jantung atau diabetes yang jika tidak diketahui akan mengganggu kesehatan rongga mulutnya. ${ }^{9}$

Berdasarkan uraian di atas, peneliti tertarik untuk menganalisis status oral higiene dan periodontal dengan membandingkan antara pasien kompromis dan non kompromis medis yang dirawat inap di rumah sakit.

\section{BAHAN DAN METODE}

Jenis rancangan ini adalah penelitian kasus kontrol yaitu penelitian yang mengidentifikasi hubungan antara kelompok efek (kasus) dengan kelompok tanpa efek (kontrol) terhadap faktor risiko. Kelompok kasus dalam penelitian ini adalah pasien kompromis medis penderita penyakit jantung dengan tekanan darah $\geq 140 / 90 \mathrm{mmHg}$ dan DM tipe 2 dengan kadar gula darah puasa $\geq 126 \mathrm{mg} / \mathrm{dL}$, sedangkan kelompok kontrol adalah pasien penyakit THT dan mata.

Populasi kasus adalah semua pasien kompromis medis yang menderita penyakit jantung dan DM tipe 2 dan tidak mendapatkan perawatan karang gigi dalam 3 bulan terakhir, yang dirawat inap pada Instalasi Penyakit Dalam dan Kardiovaskuler di Rumah Sakit Umum Pusat Haji Adam Malik Medan selama periode penelitian. Populasi kontrol adalah semua pasien yang tidak menderita kondisi kompromis medis. Sampel diambil dengan cara proportional sampling atau sampel berimbang. Besar sampel dihitung menggunakan rumus besar sampel uji hipotesis terhadap dua proporsi pada rancangan kasus kontrol sehingga diperoleh hasil perhitungan besar sampel sebanyak 60 sampel dengan perbandingan besar sampel antara kelompok kasus dan kelompok kontrol adalah 1:1, sehingga total sampel sebanyak 120 pasien.

Pengumpulan data diperoleh dari catatan rekam medis pasien rawat inap di Rumah Sakit Umum Pusat Haji Adam Malik Medan, pemeriksaan oral higiene dengan Oral Hygiene Index Simplified (OHI-S) oleh Greene dan Vermilion, serta status periodontal dengan Periodontal Disease Index (PDI) oleh Ramfjord. Etika penelitian disetujui dan dikeluarkan oleh Komisi Etik Penelitian Bidang Kesehatan Fakultas Kedokteran Universitas Sumatera Utara dengan nomor: 53/KOMET/FK USU/2015.

\section{HASIL}

Berdasarkan kelompok usia, pasien kompromis medis lebih banyak pada usia $\geq 50$ tahun $(70,0 \%)$ dibandingkan pasien non kompromis medis $(55,0 \%)$. Persentase jenis kelamin pasien kompromis medis 
lebih banyak perempuan $(61,7 \%)$ dibandingkan pasien non kompromis medis $(75,0 \%)$. Sebagian besar pasien kompromis medis dan non kompromis medis berpendidikan tamat SMA (43,3\%). Baik pasien kompromis medis $(51,7 \%)$ maupun non kompromis medis $(56,7 \%)$, lebih banyak dirawat inap $\geq 6$ hari (Tabel 1).

Tabel 1. Karakteristik pasien kompromis dan non kompromis medis

\begin{tabular}{|c|c|c|c|c|}
\hline \multirow[t]{2}{*}{ Karakteristik } & \multicolumn{2}{|c|}{$\begin{array}{c}\text { Kompromis } \\
\text { medis }\end{array}$} & \multicolumn{2}{|c|}{$\begin{array}{l}\text { Non kompromis } \\
\text { medis }\end{array}$} \\
\hline & $\mathrm{n}$ & $\%$ & $\mathrm{n}$ & $\%$ \\
\hline \multicolumn{5}{|l|}{ Usia (tahun) } \\
\hline$<50$ & 18 & 30,0 & 27 & 45,0 \\
\hline$\geq 50$ & 42 & 70,0 & 33 & 55,0 \\
\hline \multicolumn{5}{|l|}{ Jenis kelamin } \\
\hline Perempuan & 37 & 61,7 & 45 & 75,0 \\
\hline Laki-laki & 23 & 38,3 & 15 & 25,0 \\
\hline \multicolumn{5}{|l|}{ Pendidikan } \\
\hline SD & 15 & 25,0 & 7 & 11,7 \\
\hline SMP & 13 & 21,7 & 22 & 36,7 \\
\hline SMA & 26 & 43,3 & 26 & 43,3 \\
\hline PT & 6 & 10,0 & 5 & 8,3 \\
\hline \multicolumn{5}{|c|}{ Lama rawat inap (hari) } \\
\hline$<6$ & 29 & 48,3 & 26 & 43,3 \\
\hline$\geq 6$ & 31 & 51,7 & 34 & 56,7 \\
\hline
\end{tabular}

Rerata usia pasien kompromis medis adalah 53,25 $\pm 11,25$ dan pasien non kompromis medis 45,76 \pm 9,96. Rerata lama dirawat inap pasien kompromis medis adalah 5,07 $\pm 2,79$ dan pasien non kompromis medis 7,30 $\pm 4,04$ (Tabel 2).

Tabel 2. Rerata usia dan lama rawat inap pasien kompromis dan non kompromis medis

\begin{tabular}{lcc}
\hline \multirow{1}{*}{\multicolumn{1}{c}{ Pasien }} & $\begin{array}{c}\text { Usia } \\
\text { (tahun) }\end{array}$ & $\begin{array}{c}\text { Lama rawat inap } \\
\text { (hari) }\end{array}$ \\
\cline { 2 - 3 } & $\overline{\boldsymbol{x}} \pm \mathrm{SD}$ & $\overline{\boldsymbol{x}}_{ \pm \mathrm{SD}}$ \\
\hline $\begin{array}{l}\text { Kompromis medis } \\
\begin{array}{l}\text { Non kompromis } \\
\text { medis }\end{array}\end{array}$ & $53,25 \pm 11,25$ & $5,07 \pm 2,79$ \\
\hline
\end{tabular}

Rerata skor indeks debris pada pasien kompromis medis adalah 1,52 $\pm 0,30$ dan pasien non kompromis medis $1,32 \pm 0,35$. Rerata skor indeks kalkulus pada pasien kompromis medis adalah 2,08 \pm 0,54 dan pasien non kompromis medis $1,72 \pm 0,49$. Rerata skor OHIS pada pasien kompromis medis adalah 3,60 $\pm 0,77$ dan pasien non kompromis medis 3,05 $\pm 0,75$ (Tabel 3).

Persentase status oral higiene mayoritas buruk $(73,3 \%)$ pada pasien kompromis medis, sebaliknya pasien non kompromis medis mayoritas baik
$(70,0 \%)$ (Tabel 4).

Tabel 3. Rerata skor indeks debris, indeks kalkulus, dan $\mathrm{OHI}-\mathrm{S}$ antara pasien kompromis dan non kompromis medis

\begin{tabular}{lccc}
\hline \multirow{1}{*}{ Pasien } & $\begin{array}{c}\text { Indeks } \\
\text { debris }\end{array}$ & $\begin{array}{c}\text { Indeks } \\
\text { kalkulus }\end{array}$ & OHI-S \\
\cline { 2 - 4 } & $\overline{\bar{x}} \pm \mathrm{SD}$ & $\overline{\bar{x}} \pm \mathrm{SD}$ & $\overline{\bar{x}} \pm \mathrm{SD}$ \\
\hline $\begin{array}{l}\text { Kompromis } \\
\text { medis }\end{array}$ & $1,52 \pm 0,30$ & $2,08 \pm 0,54$ & $3,60 \pm 0,77$ \\
$\begin{array}{l}\text { Non kompromis } \\
\text { medis }\end{array}$ & $1,32 \pm 0,35$ & $1,72 \pm 0,49$ & $3,05 \pm 0,75$ \\
\hline
\end{tabular}

Tabel 4. Kategori oral higiene pasien kompromis dan non kompromis medis

\begin{tabular}{lcccc}
\hline \multirow{2}{*}{\multicolumn{1}{c}{ Pasien }} & \multicolumn{4}{c}{ Oral higiene } \\
\cline { 2 - 5 } & \multicolumn{2}{c}{ Buruk } & \multicolumn{2}{c}{ Baik } \\
\cline { 2 - 5 } & $\mathrm{n}$ & $\%$ & $\mathrm{n}$ & $\%$ \\
\hline Kompromis medis & 44 & 73,3 & 16 & 26,7 \\
Non kompromis medis & 18 & 30,0 & 42 & 70,0 \\
\hline
\end{tabular}

Rerata skor periodontal pasien kompromis medis adalah 3,99 $\pm 1,12$ dan pasien non kompromis medis $3,16 \pm 1,06$ (Tabel 5).

Tabel 5. Rerata skor periodontal pasien kompromis dan non kompromis medis

\begin{tabular}{lc}
\hline \multirow{1}{*}{ Pasien } & Skor Periodontal \\
\cline { 2 - 2 } & $\overline{\boldsymbol{x}_{ \pm}} \mathrm{SD}$ \\
\hline Kompromis medis & $3,99 \pm 1,12$ \\
Non kompromis medis & $3,16 \pm 1,06$ \\
\hline
\end{tabular}

Persentase pasien yang mengalami periodontitis terlihat lebih banyak pada pasien kompromis medis $(64,7 \%)$, sedangkan pasien non kompromis medis hanya 35,3\% (Tabel 6).

Tabel 6. Kategori status periodontal pasien kompromis dan non kompromis medis

\begin{tabular}{lcccc}
\hline \multirow{2}{*}{ Pasien } & \multicolumn{3}{c}{ Status periodontal } \\
\cline { 2 - 5 } & \multicolumn{2}{c}{ Periodontitis } & \multicolumn{2}{c}{ Tidak } \\
& \multicolumn{4}{c}{ periodontitis } \\
\cline { 2 - 5 } & $\mathrm{n}$ & $\%$ & $\mathrm{n}$ & $\%$ \\
\hline Kompromis medis & 33 & 64,7 & 27 & 39,1 \\
Non kompromis medis & 18 & 35,3 & 42 & 60,9 \\
\hline
\end{tabular}

Hasil analisis oral higiene terhadap pasien kompromis dan non kompromis medis menunjukkan odds ratio sebesar 6,417 (95\% CI=2,897-14,212) artinya pasien kompromis medis mengalami oral higiene 6 kali lebih buruk dibandingkan pasien non kompromis medis (Tabel 7). 
Tabel 7. Hasil analisis status oral higiene terhadap pasien kompromis dan non kompromis medis

\begin{tabular}{|c|c|c|c|c|c|c|}
\hline \multirow{3}{*}{ Pasien } & \multicolumn{4}{|c|}{ Oral higiene } & \multirow{3}{*}{$p$} & \multirow{3}{*}{ Odds ratio } \\
\hline & \multicolumn{2}{|c|}{ Buruk } & \multicolumn{2}{|c|}{ Baik } & & \\
\hline & $\mathrm{n}$ & $\%$ & $\mathrm{n}$ & $\%$ & & \\
\hline Kompromis medis & 44 & 73,3 & 16 & 26,7 & & 6,417 \\
\hline $\begin{array}{l}\text { Non kompromis } \\
\text { medis }\end{array}$ & 18 & 30,0 & 42 & 70,0 & $0,000 *$ & $(2,897-14,212)$ \\
\hline Total & 60 & 100 & 60 & 100 & & \\
\hline
\end{tabular}

Hasil analisis status periodontal terhadap pasien kompromis dan non kompromis medis menunjukkan odds ratio sebesar 2,852 (95\% CI=1,346-6,042) artinya pasien kompromis medis 3 kali lebih berisiko periodontitis dibandingkan pasien non kompromis medis (Tabel 8).

Tabel 8. Hasil analisis status periodontal terhadap pasien kompromis dan non kompromis medis

\begin{tabular}{|c|c|c|c|c|c|c|}
\hline \multirow{3}{*}{ Pasien } & \multicolumn{4}{|c|}{ Status Periodontal } & \multirow{3}{*}{$p$} & \multirow{3}{*}{$\begin{array}{l}\text { Odds } \\
\text { Ratio }\end{array}$} \\
\hline & \multicolumn{2}{|c|}{ Periodontitis } & \multicolumn{2}{|c|}{$\begin{array}{c}\text { Tidak } \\
\text { periodontitis }\end{array}$} & & \\
\hline & $\mathrm{n}$ & $\%$ & $\mathrm{n}$ & $\%$ & & \\
\hline Kompromis medis & 33 & 64,7 & 27 & 39,1 & & 2,852 \\
\hline $\begin{array}{l}\text { Non kompromis } \\
\text { medis }\end{array}$ & 18 & 35,3 & 42 & 60,9 & $0,006^{*}$ & $\begin{array}{r}(1,346- \\
6,042)\end{array}$ \\
\hline Total & 60 & 100 & 60 & 100 & & \\
\hline
\end{tabular}

\section{PEMBAHASAN}

Hasil penelitian ini menunjukkan ada hubungan yang signifikan secara statistik $(p=0,000)$ antara pasien kompromis medis dan non kompromis medis yaitu mayoritas pasien kompromis medis yang dirawat inap mempunyai oral higiene buruk $(73,3 \%)$. Hal ini mungkin disebabkan sebagian besar pasien berusia $\geq 50$ tahun, tidak adanya instruksi pelaksanaan oral higiene dan edukasi mengenai kesehatan gigi dan mulut pada pasien yang sedang dirawat inap, serta lamanya pasien dirawat inap di rumah sakit merupakan beberapa faktor risiko yang berkontribusi terhadap terjadinya oral higiene pasien yang buruk. Oral higiene yang buruk dapat menyuburkan perkembangan bakteri di rongga mulut, apabila tidak dirawat menyebabkan peradangan dan kerusakan jaringan pendukung gigi, serta terjadinya penyakit periodontal yang disertai kehilangan tulang. ${ }^{10}$ Sesuai dengan penelitian Barilli, et al. pada pasien jantung di Rumah Sakit Pendidikan Sao Paulo, Brazil yang menunjukkan adanya peningkatan prevalensi penyakit periodontal $(76,3 \%)$ dan perlunya perawatan oral higiene di rumah sakit. Juga didukung penelitian Vellasco dan Bullon pada pasien kejiwaan di Rumah Sakit Seville, Spanyol yang menyatakan bahwa $91,5 \%$ pasien memerlukan perawatan oral higiene dan $77,5 \%$ pasien memer- lukan perawatan periodontal. ${ }^{5}$

Secara garis besar, penyakit periodontal dibedakan atas gingivitis yang bersifat reversibel dan periodontitis yang bersifat ireversibel karena adanya migrasi epitel penyatu ke arah apikal dan kehilangan tulang. ${ }^{10}$ Gingivitis merupakan hasil penumpukan plak bakteri pada permukaan gigi yang berkembang akibat proses inflamasi di sekitar gingiva. Sedangkan periodontitis berkembang sebagai akibat lanjutan dari gingivitis yang tidak dirawat, biasanya disertai dengan pembentukan saku periodontal serta perubahan kepadatan dan ketinggian tulang alveolar. ${ }^{11}$ Hasil penelitian ini menunjukkan ada hubungan yang signifikan secara statistik $(p=0,006)$ antara pasien kompromis medis dan non kompromis medis yaitu mayoritas pasien kompromis medis yang dirawat inap mengalami periodontitis $(64,7 \%)$. Hal ini mungkin disebabkan kurangnya pengetahuan dan kesadaran masyarakat mengenai pentingnya menjaga kebersihan rongga mulut terutama pada pasien dengan penyakit sistemik seperti penyakit jantung dan DM, jika kebersihan rongga mulut pasien dibiarkan tidak terawat akan mengakibatkan terjadinya penyakit periodontal. Penelitian Vysniauskaite dan Vehkalahti di Lituania menyatakan bahwa menyikat gigi 2 kali sehari yaitu sesudah sarapan pagi dan sebelum tidur malam berkontribusi menghasilkan kesehatan periodontal lebih baik dan menyarankan sebaiknya perilaku menyikat gigi ini selalu dianjurkan kepada pasien setiap melakukan kunjungan berkala ke dokter gigi. ${ }^{12}$

Hasil penelitian menunjukkan odds ratio oral higiene terhadap pasien rawat inap kompromis medis 6,4 dan odds ratio periodontitis 2,8. Hal ini mungkin disebabkan jumlah sampel penelitian yang sedikit. Secara statistik, jumlah sampel penelitian mempengaruhi hasil odds ratio yang diperoleh. Jumlah sampel penelitian yang kecil akan menghasilkan odds ratio yang besar, namun sebaliknya jumlah sampel yang besar akan menghasilkan odds ratio yang kecil seperti penelitian yang dilakukan Marjanovic dan Buhlin di Fakultas Kedokteran Gigi Karolinska, Swedia menyatakan odds ratio periodontitis terhadap penyakit jantung 1,79 dan odds ratio periodontitis terhadap DM 2,95 dengan jumlah total sampel penelitian sebesar 474 pasien. ${ }^{9}$

Sebagai kesimpulan, pasien kompromis medis terutama penyakit jantung dan DM tipe 2 mempunyai oral higiene 6 kali lebih buruk dan 3 kali lebih berisiko periodontitis dibandingkan pasien non kompromis medis. Hal ini mungkin disebabkan adanya gangguan pada kesehatan sistemik pasien kompromis medis seperti kontrol glikemik yang buruk dan tekanan darah yang tinggi menyebabkan kondisi kesehatan rongga mulutnya berbeda dengan pasien 
non kompromis medis sehingga menyulitkan pasien memelihara kesehatan gigi dan mulutnya.

\section{Daftar Pustaka}

1. Lockhart PB. Oral medicine and medically complex patients. $6^{\text {th }}$ ed. Oxford: John Wiley \& Sons Inc. 2013: 1-2.

2. Broderick D. Medically compromised patients: part 1. Dent Nurs 2009; 5 (1): 19-25.

3. Dhanuthai K, Sappayatosok K, Bijaphala P, Kulvit $\mathrm{S}$, Sereerat T. Prevalence of medically compromised conditions in dental patients. Med Oral Patol Oral Cir Bucal 2009; 14 (6): 287-91.

4. Neto AC, De Paula Ramos S, Sant'ana ACP, Passanezi E. Oral health status among hospitalised patients. Int J Dent Hyg 2011; 9: 21-9.

5. Barilli AL, Passos AD, Marin-Neto JA, Franco LJ. Periodontal disease in patients with ischemic coronary atherosclerosis at a University Hospital. Arq Bras Cardiol 2006; 87(6): 635-40.

6. Marjanovic M, Buhlin K. Periodontal and systemic diseases among Swedish dental school patients-a retrospective register study. Oral Health Prev Dent 2013; 11: 49-55.

7. Kementerian Kesehatan RI. Riset Kesehatan Dasar 2013. Jakarta, 2013: 114-5.

8. Situmorang N. Dampak karies gigi dan penyakit periodontal terhadap kualitas hidup. Pidato Pengukuhan Jabatan Guru Besar Tetap. Medan: Universitas Sumatera Utara, 2005: 8.

9. Bhateja S. High prevalence of cardiovascular diseases among other medically compromised conditions in dental patients: a retrospective study. J Cardio Dis Res 2012; 3: 113-6.

10. Genco RJ, Williams RC. Periodontal disease and overall health: a clinician's guide. Online version ed. Pennsylvania: Prof Audience Comm Inc, 2010: 5-6.

11. Hinrichs JE, Novak MJ. Classification of diseases and conditions affecting the periodontium. In: Newman MG, Takei HH, Klokkevold PR, Carranza FA, eds. Carranza's clinical periodontology. $11^{\text {th }} \mathrm{ed}$. St Louis: Elsevier Saunders. 2012: 41-2.

12. Vysniauskaite $S$, Vehkalahti MM. Impacts of toothbrushing frequency on periodontal findings in group elderly Lithuanians. Oral Health Prev Dent 2009; 7 : 129-36. 